\title{
Psychometric properties of the movement-specific reinvestment scale for Chinese children
}

\author{
Fiona C.M. Ling ${ }^{\mathrm{a} *}$, Jon Maxwell ${ }^{\mathrm{b}}$, Rich S.W. Masters ${ }^{\mathrm{c}}$, Alison M. McManus ${ }^{\mathrm{d}}$ and \\ Remco C.J. Polman ${ }^{\mathrm{e}}$
}

${ }^{a}$ Physical Education and Sport Sciences Department, University of Limerick, Limerick, Ireland; ${ }^{b}$ Institute of Human Performance, The University of Hong Kong, Hong Kong SAR, People's Republic of China; 'Sport and Leisure Studies Department, The University of Waikato, Waikato, New Zealand; ${ }^{\mathrm{d}}$ School of Health \& Exercise Sciences, University of British Columbia, Okanagan, Kelowna, British Columbia, Canada; ${ }^{\mathrm{E} I n s t i t u t e}$ of Sports, Exercise \& Active Living, Victoria University, Melbourne, Australia

(Received 5 May 2014; accepted 19 December 2014)

\begin{abstract}
The propensity for movement-specific reinvestment (conscious attention to and control of body movements) is associated with disrupted movement in a variety of circumstances. Movementspecific reinvestment has been shown in adults but not in children, as a validated psychometric instrument for children does not exist. The aim of this study was to examine the psychometric properties of a movement-specific reinvestment scale adapted specifically for Chinese children (MSRS-CC). Five hundred and thirty-two Chinese pre-adolescents aged 7-12 yrs completed the MSRS-CC and a sub-sample completed the questionnaire again three weeks later. Another sub-sample also completed the Coordination and Health subscales of the Physical Self-Description Questionnaire (short form; PSDQ-S). All questionnaires were completed during normal school days. A random half of sub-sample two completed the MSRS-CC before the PSDQ-S and the other half completed the questionnaires in reverse order. Confirmatory factor analyses demonstrated sound internal validity for the Scale's two-factor model. Acceptable internal reliability and satisfactory test-retest reliability were evident. Convergent and discriminant validity with the Coordination and Health subscales of the PSDQ-S was also tested, but the former was unexpectedly low. Future research using objective measures of motor proficiency was recommended. The MSRS-CC is potentially a valuable tool for understanding movement control by children in research as well as in clinical and educational settings.
\end{abstract}

Keywords: motor proficiency; physical activity; children; confirmatory factor analysis; health

Increasingly, research evidence indicates that motor proficiency is an important contributor to sport participation, habitual physical activity and sedentary behaviour in youth (Barnett, van Beurden, Morgan, Brooks, \& Beard, 2009; Hardy, Reinten-Reynolds, Espinel, Zask, \& Okely, 2012). Poor motor proficiency can negatively influence physical and psychological development. Low gross motor competence is associated with poorer aerobic and anaerobic capacity, lower muscle strength and metabolic syndrome, which can potentially extend into adolescence (Cairney, Hay, Veldhuizen, \& Faught, 2011; Hands, 2008). Psychologically, children with low motor proficiency are more likely to experience psychosocial and emotional difficulties, including

*Corresponding author. Email: fiona.ling@ul.ie

This article was originally published with errors. This version has been corrected. Please see Corrigendum (http://dx.doi.org/10.1080/1612197X.2015.1034339). 
low self-esteem, depression and anxiety (Lingam et al., 2012; Piek, Baynam, \& Barrett, 2006; Pratt \& Hill, 2011). Additionally, children with less proficient fine motor skills have been shown to perform worse academically (Chang \& Yu, 2010), so there seems little doubt that motor competence plays a critical role in the well-being and everyday functioning of children (Rivilis et al., 2011; Wang, Tseng, Wilson, \& Hu, 2009).

In adults, the propensity for movement-specific reinvestment (conscious attention to and control of body movements) has been linked to motor proficiency in situations in which motivation to move effectively is elevated (Masters \& Maxwell, 2008; Masters, Polman, \& Hammond, 1993). Masters and colleagues argued that a variety of contingencies, including anxiety, fear, boredom, fatigue and movement difficulties or disorders, could result in conscious attempts to oversee the execution of well-practiced movements that are better left to run automatically. The role of reinvestment in movement disruption has been demonstrated in various adult populations (see Masters \& Maxwell, 2008). For example, numerous studies have shown that under psychological pressure people with a high propensity for reinvestment are more likely to display disrupted performance of sports tasks, such as soccer kicking (Chell, Graydon, Crowley, \& Child, 2003), golf putting (Maxwell, Masters, \& Poolton, 2006) and hockey dribbling (Jackson, Ashford, \& Norsworthy, 2006). In a clinical context, elderly fallers (Wong, Masters, Maxwell, \& Abernethy, 2008), and people with Parkinson disease (Masters, Hall, MacMahon, \& Eves, 2007) or stroke (Orrell, Masters, \& Eves, 2009) have all been found to have a greater propensity for movement-specific reinvestment than age-matched controls. Masters et al. (2007) also found that duration of Parkinson disease was associated with propensity for reinvestment, suggesting that the tendency towards conscious control of movements increased over time. Similarly, Orrell et al. (2009) found that functional impairment following stroke was associated with propensity for reinvestment and duration of rehabilitation. In surgical practice, propensity for reinvestment has also been shown to be associated with slowed laparoscopy performance by medicals students under time pressure (Malhotra, Poolton, Wilson, Ngo, \& Masters, 2012).

Evidence of a mediating role of movement-specific reinvestment in motor performance seems unequivocal in adults, but it is unclear, at this stage, whether reinvestment plays a role in motor performance by children. Evidence suggests that relatively young children may be more likely to consciously control their motor performance if they learn skills, such as throwing, with too much explicit knowledge of how to execute the movements (Capio, Poolton, Sit, Eguia, \& Masters, 2013; Capio, Poolton, Sit, Holmstrom, \& Masters, 2013; Maxwell, Masters, \& Hammond, 2008), but whether movement-specific reinvestment is facilitative or debilitative to motor performance in young children is yet unknown partly due to the absence of a validated psychometric instrument to measure movement-specific reinvestment in this population. Following the early development of a Reinvestment Scale (Masters et al., 1993) that was not specific to movement, the Movement-Specific Reinvestment Scale (MSRS) was developed (Masters, Eves, \& Maxwell, 2005), which has been widely utilised to measure the propensity for conscious control by adults, and has been validated in a variety of ethnic populations (Kleynen et al., 2013; Masters et al., 2005; Wong et al., 2008). The scale is comprised of two subscales, one that gauges the tendency to attend to and control the mechanics of one's movements, conscious motor processing (CMP), and one that gauges the tendency to be self-conscious about the style of one's movement, movement self-consciousness (MSC). Despite the sound psychometric properties of the MSRS for adults (Masters et al., 2005), as well as its Chinese version (Wong et al., 2008), it is crucial to ascertain that the modified version of the MSRS for the child population is indeed measuring the intended construct and that the language used is comprehensible for young children of all ages due to the relatively varied cognitive development during childhood (Ling, McManus, Masters, \& Polman, 2014).

Therefore, the aim of the current study was to adapt and validate a Chinese version of the MSRS (Wong et al., 2008) for use in Chinese pre-adolescents aged between 7 and 12 years. Existing 
evidence suggests that compared to the children in the west, Chinese Hong Kong children exhibited more superior fundamental motor ability such as jumping, running and hopping (Pang \& Fong, 2009), however, whether the observed difference might be attributable to Chinese children possessing a relatively lower propensity for movement reinvestment remains unknown and, as previously indicated, no existing psychometric instruments are available to investigate such possibility. Besides investigating the internal validity and internal consistency of the adapted movement-specific reinvestment scale for Chinese children (MSRS-CC), we also examined its convergent and discriminant validity against the Coordination and Health subscales of the Physical Self-Description Questionnaire (short form) (PSDQ-S; Marsh, Martin, \& Jackson, 2010). The PSDQ-S assesses 11 aspects of children's physical self-concept, and for the current study, only the Coordination and Health subscales were used, which measure self-perceived coordination and self-perceived health, respectively. We hypothesised that scores on the MSRS-CC would correlate moderately (.50 to .70) and negatively with scores on the Coordination subscale (convergent validity), as movement reinvestment has shown to impede motor performance in adults as previously mentioned, and poorly (less than .25) with scores on the Health subscale (discriminant validity) as the tendency to consciously control body movements might have a rather indirect link with one's perceived health (Portney \& Watkins, 2000). We also conducted gender comparisons in the propensity for movement-specific reinvestment. While evidence for gender differences in gross motor proficiency, such as running, agility and ball throw, has been equivocal, girls demonstrated more superior proficiency in timed tasks such as balancing and finger sequencing (Larson et al., 2007; Wrotniak, Epstein, Dorn, Jones, \& Kondilis, 2006). For this reason, no specific predication has been proposed for gender differences in the propensity for movement reinvestment.

Method

Participants

Parental consent and child assent were obtained from children aged 7-12 years $(\mathrm{n}=532$, mean age $=9.66$ yrs $\pm 1.13 ; 52.6 \%$ boys) in Grade $2-6$ of three local government-aided schools in Hong Kong. Participants completed the MSRS-CC at time 1 and a sub-sample of 246 participants (sub-sample 1) completed the questionnaire again 3 weeks later (time 2) for the test-retest reliability assessment. A second sub-sample of 266 participants (sub-sample 2) completed the Coordination and the Health subscales of the PSDQ-S at time 1. No significant age or gender composition differences were noted between the larger sample and the sub-samples. All measures and procedures were approved by the Institutional Review Board for Human Ethics.

\section{Measures}

Movement-Specific Reinvestment Scale - Chinese (MSRS-C): The MSRS-C (Wong et al., 2008) was translated-back-translated and adapted from the original MSRS (Masters et al., 2005). The 10-item MSRS measures the propensity to consciously attend to and control movements and comprises two factors - CMP (example item: I reflect about my movement a lot) and MSC (example item: I am concerned about my style of movement). Each item is anchored at its extremes by 1 (strongly disagree) and 6 (strongly agree). Higher scores suggest a greater propensity for reinvestment. The MSRS-C demonstrates good internal validity, sound discriminant and predictive validity for use in Chinese adults (Wong et al., 2008).

Physical Self-Description Questionnaire - short form (PSDQ-S) (Chinese version): The PSDQ-S (Marsh et al., 2010) was developed from the PSDQ (Marsh, Richards, Johnson, Roche, \& 
Tremayne, 1994), which was designed to measure 11 aspects of physical self-concept in adolescents. The PSDQ has been modified and translated to different languages and has consistently shown sound psychometrics across cultures, including Australian, Spanish and Turkish (Marsh, Marco, \& Abçý, 2002). It was later translated and validated for use in Chinese pre-adolescents and the Chinese version has demonstrated excellent psychometric properties, including internal consistency ( $\alpha=.74)$, internal validity, and predictive validity, comparable to those of the original PSDQ (Hau, Sung, Yu, Marsh, \& Lau, 2005). For the purposes of the current study, only the Coordination subscale (example item: I am good at coordinated movements) and the Health subscale (example item: I get sick a lot) were utilised. Each subscale comprises five items, with answers ranging from 1 (True) to 6 (False).

\section{Procedure}

MSRS-CC modification: In the development of the MSRS-CC, wordings on the MSRS-C were simplified. Based on the first author's experience in questionnaire development for this population, all items were changed from the statement format to a question format, as the first-person statements (e.g. "I reflect about my movement a lot") seemed to be particularly challenging to comprehend than the third-person questions (e.g. "Would you think about the body movement you've performed?") especially for the younger children partly because the instructions are in third person (see Appendix 1). Three teachers from the recruited schools who were experienced in teaching various grades were also consulted in the content and answer format of the modified questionnaire in terms of its comprehensiveness for the different age groups, and minor changes in the wording were made accordingly. Following this, pilot testing of the modified instrument was initially conducted on 3-5 participants from each grade who were encouraged to ask for clarification should any expressions were unclear to them. The pilot testing revealed that, although the wordings appeared to be comprehensible to all age groups, the majority of participants had difficulty interpreting the six response categories when differences between the proximal points in the scale were frequently questioned. Subsequently, we modified the categories using a four-point scale, which has less ambiguity than a five-point scale that contains a mid-point, and yet retains enough range of choice to maintain response stability (Streiner \& Norman, 2008; Weng, 2004). The re-modified scale was again pilot-tested with four participants from each age group. Despite that a few clarifications were requested especially from the youngest age group, they were primarily for confirmation of their understanding rather than for reiteration of the meaning. Thus, no further modifications were made to the questionnaire. The MSRS (English) and the MSRS-CC are shown in Appendix 1.

Questionnaire administration: Completed parental consent forms were returned to the school teachers who then made arrangements for the questionnaires to be completed during class. To counterbalance possible order effects when the PSDQ-S subscales and the MSRS-CC were presented at time 2, a random selection of half of the participants completed the MSRS-CC followed by the PSDQ-S three to five days later, whereas the remaining participants completed the questionnaires in the reverse order. All questionnaires were self-administered. A researcher or a teacher was present to answer any questions or to read out the items if comprehension was an issue especially for the younger children.

Analysis strategy

After checking for univariate normality of the data, using Finney and DiStefano's (2006) recommendations (absolute values of skewness and kurtosis not exceeding 2 and 7 respectively) and multivariate normality of the data following Kline's (2012) recommended critical ratio cut- 
off of 8.0, the entire sample was randomly divided so that half could be used as a confirmatory sample and half could be used as a cross-validation sample to test invariance of the factor structure of the two-factor model (Anderson \& Gerbing, 1988). Confirmatory factor analyses (CFAs) based on maximum likelihood estimation and a covariance matrix were conducted using AMOS 5.0 software (Arbuckle, 2003) for structural equation modelling. The factor structure of the MSC and the CMP was first assessed separately (using the confirmatory sample) before combining them for analysis of the two-factor model (using the confirmatory and the cross-validation samples) (Byrne, 2010). Lambda was set at 1 for the first observed indicator of each latent variable (i.e. MSC and CMP) and the error weights, and all other parameters were allowed to be freely estimated. The goodness-of-fit indices used to detertmine the model fit of the MSRS-CC include: (1) the chisquare statistics (a non-significant p-value would suggest an acceptable model fit though it could be sensitive to sample size, with a larger sample size more likely to demonstrate a significant chisquare statistics despite minor discrepancies between the data and the model; Anderson \& Gerbing, 1988), (2) the standardised root mean square residual (SRMR; less than or equal to .08 for a good fit), (3) the root mean square error of approximation (RMSEA; close to or less than .06 for a good fit), including its $90 \%$ confidence interval (CI; < .05 (lower bound) and $<.08$ (upper bound) as acceptable; 0 (lower bound) and <.05 (upper bound) as good fit; Browne \& Cudeck, 1993), (4) the goodness of fit index (GFI) and (5) the comparative fit index (CFI; greater than or equal to .95 for a good fit and .90 for an adequate fit; Hu \& Bentler, 1999). Model modification was carried out using chi-square statistics, cross-correlation of error terms given that there is a substantive theoretical justification for it, for example, similarity in the content of the items concerned (Byrne, 1994), modification indices (MIs) and factor loadings (greater than or equal to .34 was considered acceptable; Stevens, 2002). In addition to testing the factor structure for the entire sample, factorial invariance was also tested for the different age groups concerned - good validity for one age group may mask poor validity for another age group, especially when understanding of a construct can vary as a consequence of cognitive developmental differences in young children (Cremeens, Eiser, \& Blades, 2006; Ling et al., 2014). Therefore, to ensure structure invariance between the different ages, the entire sample was split into three age groups (7-8, 9-10, 11-12 years) and multi-group comparison was conducted by constraining all measurement weights and structural covariances to be equal in our final model for the MSRS-CC (a non-significant chi-square change from the constrained to the unconstrained model would suggest factorial invariance between the age groups). This was followed by examination of the internal consistency of the MSC and CMP (approximately .70 or above as acceptable depending on the number of items in the scale and the construct it was designed to measure; Cortina, 1993; Kline, 1999; Tabachnick \& Fidell, 2007), and test-retest reliability of sub-sample 1 analysed with intraclass correlation with 95\% CI using a two-way random model (intraclass correlation coefficient (ICC) of .81 or above classified as "excellent”, .61-.80 as "good”, .41-.60 as "moderate” and .40 or below as "poor”; Nunnally \& Bernstein, 1994). The convergent and discriminant validity of the MSRS-CC and the MSC and CMP subscales (using the Coordination subscale and the Health subscale of the PSDQ-S) were also tested by Pearson product-moment correlation analyses.

After the validation procedure, gender differences were examined using multi-group comparisons to ascertain factorial invariance between the gender groups. Gender differences in the full MSRS-CC and in the MSC and CMP subscales were then tested using analyses of variance (ANOVAs).

\section{Results}

\section{MSRS-CC internal validity}

An inspection of the skewness and kurtosis values for the 10 items ( -0.48 to 0.19 and -1.16 to -0.37 , respectively) (to indicate univariate normality) and the critical ratio of 7.42 (to indicate 
multivariate normality), revealed that the data were normally distributed. We thus proceeded with CFAs for the scale. Based on the confirmatory sample, the factor structure of the MSC subscale demonstrated an excellent model fit $\left(\chi^{2}[5]=5.03, \mathrm{p}>.05\right.$; SRMR $=0.03$; RMSEA $(90 \% \mathrm{CI})=$ $0.00(0.00-0.08)$; CFI = 1.00; GFI = 0.99). As for the CMP subscale, perusal of the MIs suggested a correlation between the error terms of item 4 ("I try to think about my movements when I carry them out”) and 7 ("I am aware of the way my body works when I am carrying out a movement"). On inspection of the items, it was noted that both are concerned with thoughts about body movements during execution. This lends theoretical support for correlating the error terms of the two items and the subsequent model fit has improved from $\left(\chi^{2}[5]=19.71, \mathrm{p}<.05\right.$; SRMR $=0.05$; RMSEA (90\% CI) $=0.11(0.06-0.16) ; \mathrm{CFI}=0.94 ; \mathrm{GFI}=0.97)$ to $\left(\chi^{2}[4]=9.33, \mathrm{p}>.05\right.$; SRMR $=0.03$; RMSEA $(90 \% \mathrm{CI})=0.06(0.00-0.08) ; \mathrm{CFI}=0.98 ; \mathrm{GFI}=0.99)$.

The MSC model and the re-specified CMP model were then combined into one analysis, but the two-factor model demonstrated a relatively poor model fit $\left(\chi^{2}[33]=94.52, \mathrm{p}<.05\right.$; SRMR $=$ 0.06; RMSEA $(90 \%$ CI $)=0.08(0.06-0.10)$; CFI $=0.89$; GFI $=0.94)$. The MIs indicated correlations of error terms for two pairs of items - items 1 ("I remember the times when my movements have failed me") and 9 ("I try to figure out why my actions failed") as well as items 5 and 10. On inspection of the four items, it was again noted that each of these pairs shares similar meaning about reflection on one's own body movement, with items 1 and 9 concern with past failure in executing body movements while items 5 and 10 concern with being self-conscious about body movements. This observation has provided an appropriate theoretical ground for proceeding with the correlation of the respective error terms, resulting in an improvement of model fit $\left(\chi^{2}[31]\right.$ $=50.39, \mathrm{p}<.05 ; \mathrm{SRMR}=.04$; RMSEA $(90 \% \mathrm{CI})=0.05$ (0.02-0.07); CFI = 0.97; GFI = 0.96). Factor loadings of this two-factor model ranged from 0.36 to 0.65 . Given the adequate sample size, we accepted this model for further analyses despite the significant chi-square statistics which is somewhat sensitive to sample size (Anderson \& Gerbing, 1988). Results of the CFA for the cross-validation sample demonstrated a satisfactory model fit $\left(\chi^{2}[31]=61.19, \mathrm{p}<.05\right.$; $\operatorname{SRMR}=0.05$; RMSEA $(90 \% \mathrm{CI})=0.06(0.04-0.08)$; CFI $=0.92$; GFI $=0.96)$ with factor loadings ranging from 0.40 to 0.70 . Considering that there did not appear to be other substantive theoretical reasons for re-specifying the factor structure of the scale, no further changes were made to this two-factor model. Summary of the model fit indices for the original and the re-specified models was provided in Table 1.

To ensure factorial invariance between the three age groups, multi-group comparisons were carried out ( $\mathrm{n}=105,348$ and 79 for $7-8$ yrs, 9-10 yrs and 11-12 yrs, respectively). Data for the three age groups appeared to fit the confirmed two-factor model $\left(\chi^{2}[93]=189.92, \mathrm{p}<.05\right.$; SRMR $=0.06$; RMSEA $(90 \%$ CI $)=0.04(0.04-0.05)$; CFI $=0.91$; GFI $=0.94)$ and a non-significant chi-square change from the constrained to the unconstrained model suggested factorial invariance across the three age groups $\left(\chi^{2}[16]=9.09, \mathrm{p}=.91\right)$.

MSRS-CC internal consistency, test-retest reliability, convergent and discriminant validity

Table 2 presents a summary of the internal consistency and test-retest reliability of the MSRS-CC and the MSC and CMP subscales, as well as their respective scores for both genders at time 1 and time 2. Based on the entire sample, both MSC and CMP demonstrated acceptable internal consistency with Cronbach's alpha $(\alpha)$ of 0.68 and 0.67 , respectively, considering that (a) the scale is comprised of only 10 items (i.e. a larger number of items in a questionnaire is likely to generate a greater $\alpha$ than one with fewer items) (Cortina, 1993), (b) the scale was designed to measure a psychological construct for which an $\alpha$ below 0.70 is even expected due to the complexity of processes involved (see Dunn, Baguley \& Brunsden, 2014 for details) and (c) our results were not far 
Table 1. Model fit indices and factor loading range of the original and the modified model for the MSRSC-C and its factors.

\begin{tabular}{|c|c|c|c|c|c|c|c|c|c|c|c|}
\hline & & Modification steps & $\chi^{2}$ & $\mathrm{df}$ & $\mathrm{p}$ & SRMR & RMSEA & $90 \%$ CI & CFI & GFI & $\begin{array}{l}\text { Factor } \\
\text { loadings }\end{array}$ \\
\hline MSC & Original factor structure & _- & 5.03 & 5 & 0.41 & 0.03 & 0.00 & $0.00-0.09$ & 1.00 & 0.99 & $0.37-0.83$ \\
\hline \multirow[t]{2}{*}{ CMP } & Original factor structure & - & 19.71 & 5 & $0.00 *$ & 0.05 & 0.11 & $0.06-0.16$ & 0.94 & 0.97 & $0.45-0.71$ \\
\hline & Model modification & $\begin{array}{l}\text { Correlate error terms for } \\
\text { items } 4 \text { and } 7\end{array}$ & 9.33 & 4 & 0.05 & 0.03 & 0.06 & $0.00-0.08$ & 0.98 & 0.99 & $0.41-0.74$ \\
\hline \multirow[t]{3}{*}{ MSRS-CC } & $\begin{array}{l}\text { Original factor structure } \\
\text { (confirmatory sample) }\end{array}$ & - & 94.52 & 33 & $0.00 *$ & 0.06 & 0.08 & $0.06-0.10$ & 0.89 & 0.94 & $0.42-0.64$ \\
\hline & Model modifications & $\begin{array}{l}\text { Correlate error terms for } \\
\text { items } 1 \text { and } 9\end{array}$ & 74.11 & 32 & $0.00 *$ & 0.05 & 0.07 & $0.05-0.09$ & 0.92 & 0.95 & $0.42-0.63$ \\
\hline & & $\begin{array}{l}\text { Correlate error terms for } \\
\text { items } 5 \text { and } 10\end{array}$ & 50.39 & 31 & $0.02 *$ & 0.04 & 0.05 & $0.02-0.07$ & 0.97 & 0.96 & $0.36-0.65$ \\
\hline MSRS-CC & $\begin{array}{l}\text { Modified factor structure (cross- } \\
\text { validation sample) }\end{array}$ & - & 61.19 & 31 & $0.00 *$ & 0.05 & 0.06 & $0.04-0.08$ & 0.92 & 0.96 & $0.40-0.70$ \\
\hline
\end{tabular}

Note: MSRSC-C, movement-specific reinvestment scale for children - Chinese; MSC, movement self-consciousness; CMP, conscious motor processing, $\chi^{2}=$ chi-square; df, degree of freedom; SRMR, standardised root mean square; RMSEA, root mean square error of approximation; $90 \% \mathrm{CI}$, $90 \%$ confidence interval of the RMSEA; CFI, comparative fit index. $* \mathrm{p}<.05$ (two-tailed). 
Table 2. Internal consistency and test-retest reliability of MSRSC-C, MSC and CMP and their respective mean \pm SD scores for boys and girls in time 1 and time 2 as well as ANOVA results for gender comparison.

\begin{tabular}{lcccccc}
\hline & & $\begin{array}{c}\text { Time } 1 \text { mean } \\
\pm \text { SD }(\mathrm{n}= \\
\text { 532) }\end{array}$ & $\begin{array}{c}\text { Time 2 mean } \\
\pm \text { SD }(\mathrm{n}= \\
266)\end{array}$ & $\begin{array}{c}\text { Internal } \\
\text { consistency }\end{array}$ & $\begin{array}{c}\text { Test-retest } \\
\text { reliability } \\
\text { (ICC) }\end{array}$ & $\begin{array}{c}\text { Gender differences } \\
\text { (ANOVA) }\end{array}$ \\
\hline MSRS-CC & Boys & $26.27 \pm 5.17$ & $26.34 \pm 5.68$ & 0.77 & $0.62(95 \% \mathrm{CI}$, & $\mathrm{F}(1,531)=2.34, \mathrm{p}$ \\
& Girls & $26.41 \pm 5.37$ & $26.34 \pm 5.13$ & & $0.50-0.71)$. & $=.13, \eta^{2}=0.004$ \\
MSC & Boys & $12.55 \pm 3.11$ & $12.71 \pm 3.12$ & 0.68 & - & $\mathrm{F}(1,531)=3.21, \mathrm{p}$ \\
& Girls & $12.71 \pm 3.12$ & $13.17 \pm 3.39$ & & & $=.07, \eta^{2}=0.001$ \\
CMP & Boys & $13.71 \pm 2.85$ & $13.64 \pm 2.92$ & 0.67 & - & $\mathrm{F}(1,531)=0.62, \mathrm{p}$ \\
& Girls & $13.70 \pm 2.98$ & $13.34 \pm 2.73$ & & $.43, \eta^{2}=0.004$ \\
\end{tabular}

Note: MSRS-CC, movement-specific reinvestment scale for children - Chinese; MSC, movement self-consciousness; CMP, conscious motor processing; ANOVA, analysis of variance; ICC, intraclass correlation coefficient; CI, confidence interval.

off from the 0.70 recommendation. For sub-sample 1, a good test-retest reliability was noted for the MSRS-CC, with an ICC of 0.62 (95\% CI, 0.50-0.71).

Regarding the convergent and discriminant validity, the Coordination subscale and the Health subscale of the PSDQ-S demonstrated acceptable internal consistency in sub-sample $2(\alpha=0.76$ and 0.77 respectively). Thus, we proceeded to examination of their correlation with the MSRSCC and the MSC and CMP subscales. Pearson's product moment correlations indicated that score on the MSRS-CC was significantly correlated with score on the Coordination subscale $(r=.18$, $p$ $<.01)$, but not with score on the Health subscale $(\mathrm{r}=.07, \mathrm{p}=.24)$. Further investigation showed that for the subscales, score on CMP was significantly related to score on the Coordination subscale $(\mathrm{r}=.21, \mathrm{p}<.01)$. However, significant correlations were not evident between CMP and the Health subscale $(\mathrm{r}=.11, \mathrm{p}=.07)$, MSC and the Coordination subscale $(\mathrm{r}=.11, \mathrm{p}=.08)$ or MSC and the Health subscale $(r=.02, p=.77)$. Details of the correlation results can be found in Table 3 .

\section{Gender comparisons}

Further CFA showed that the data for boys and girls fit the two-factor model generated in the previous analyses $\left(\chi^{2}[62]=100.28, \mathrm{p}<.01\right.$; SRMR $=0.05$; RMSEA $(90 \% \mathrm{CI})=0.03(0.02-0.05)$; $\mathrm{CFI}=0.96$; $\mathrm{GFI}=0.97)$. A non-significant Chi-square change from the unconstrained to the constrained model $\left(\chi^{2}[8]=5.62, p=.69\right)$ suggested that the data for both genders shared the same factorial structure (i.e. the items and factors in the Scale appeared to measure the same theoretical construct for both genders), allowing direct comparisons of their MSRS-CC scores. ANOVA

Table 3. Pearson product moment correlation results for the convergent and discriminant validity of the MSRS-CC, MSC and CMP with the PSDQ-S Coordination subscale and the Health subscale.

$\begin{array}{cr}\begin{array}{c}\text { PSDQ-S Coordination subscale } \\ (\mathrm{n}=266, \text { mean }=23.22 \pm 4.89)\end{array} & \begin{array}{r}\text { PSDQ-S Health subs } \\ (\mathrm{n}=266, \text { mean }=21.48\end{array} \\ \mathrm{r}=.18, \mathrm{p}=.003^{* *} & \mathrm{r}=.07, \mathrm{p}=.24 \\ \mathrm{r}=.11, \mathrm{p}=.08 & \mathrm{r}=.02, \mathrm{p}=.77 \\ \mathrm{r}=.21, \mathrm{p}=.001^{* *} & \mathrm{r}=.11, \mathrm{p}=.07\end{array}$

Note: MSRS-CC, movement-specific reinvestment scale for chinese children; MSC, movement self-consciousness; CMP, conscious motor processing; PSDQ-S,-- physical self-description questionnaire (short form); r, Pearson product moment correlation coefficient.

** $\mathrm{p}<.01$ (two-tailed). 
revealed no significant differences between the genders in their overall MSRS-CC, MSC or CMP scores (see Table 2 for a summary of gender comparisons on the respective scores).

\section{Discussion}

To our knowledge, this is the first attempt to develop a psychometric instrument to measure movement-specific reinvestment in young children. Our results demonstrate that the MSRS-CC possesses acceptable internal validity and internal consistency. Despite the cross-correlation of error terms for a few items, which may indicate similarity of content, no items were deleted from the questionnaire as subtle content differences remained detectable. Our findings suggest that the same two-factor structure applies to ages ranging from 7 to 12 years, implying that the MSRS-CC appraises the same construct for the entire age range. Test-retest reliability also appeared to be satisfactory. Despite the significant correlation between the MSRS-CC and the Coordination subscale of the PSDQ-S, our result was unexpected due to the low positive correlation. Further examination indicated that CMP but not MSC was correlated significantly with the Coordination subscale, which is perhaps unsurprising considering that items from the Coordination subscale, such as "I am good at coordinated movements" probably represent the mechanics (i.e. CMP) rather than the style of movement (i.e. MSC). Additionally, movement-specific reinvestment may not have a similar direct and negative relationship with motor proficiency, and motor performance, in young children compared to adults, as there exists some evidence to suggest that the effect of age might moderate the relationship where dispositional self-consciousness could enhance young children's motor performance but was likely to impair that of adolescents (Tice, Buder, \& Baumeister, 1985). Moreover, research seems to suggest that self-efficacy could be a prominent factor affecting children's motor proficiency/motor performance in both clinical and non-clinical child populations (Peens, Pienaar, \& Nienaber, 2008; Wrontniak et al., 2006). These empirical evidence may partially explain our unexpected findings in the non-significant association, and the relatively low yet significant and positive correlation, between selfreport coordination and MSC and CMP respectively in our pre-adolescent sample. Future research is encouraged to take into account self-efficacy in the investigation of movement reinvestment, motor proficiency and/or motor performance.

In addition, no gender differences were observed with respect to propensity for reinvestment which may simply imply that factors other than movement-specific reinvestment contribute to coordination, such as biological differences (Thomas \& French, 1985) and/or gender-specific activity participation (Harrell et al., 2003). Of course, it is also possible that significant gender differences in the propensity for movement-specific reinvestment do not emerge until adolescence when gender differences in gross motor proficiency (e.g. locomotor skills and object control) become more apparent (Booth et al., 2006; Thomas \& French, 1985).

Despite the growing body of research into movement-specific reinvestment in adults, our understanding of its influence on the motor competence of children, and their subsequent physical activity and sport participation behaviour, is limited. Our study has shown that the MSRS-CC may be a useful tool to further understanding of movement reinvestment in Chinese pre-adolescents; however, future research is encouraged to examine the construct and predictive validity of the Scale. Recently, neuropsychological evidence has emerged to defend the construct validity of the Scale. People who score high on the CMP subscale, for example, display greater co-activation between the verbal-analytical (left temporal) and motor-planning (frontal midline) regions of the cortex during movement than people who score low on the Scale (Zhu, Poolton, Wilson, Maxwell, \& Masters, 2011). Whether similar findings can be expected in children is of both theoretical and clinical interest. Furthermore, greater understanding of the role of movement reinvestment in motor competence can potentially benefit physical education teachers and sports coaches 
who wish to design better coaching practices, and paediatric professionals who wish to design and assess interventions for children with developmental motor impairments.

Some limitations of the current study are worth noting. First, caution is warranted when administering the MSRS-CC to younger children. In some cases, limited linguistic abilities may require aids to comprehension from an experienced instrument administrator. Moreover, although the PSDQ-S has demonstrated strong psychometric properties and that self-perceived coordination has been used as a proxy of motor performance, objective measures of coordination, such as assessments of fundamental motor skills, should be used to examine the relationship between movement reinvestment, motor proficiency and motor performance in children. Lastly, the relatively disproportionate age group samples may be of statistical concern, although the sizeable overall sample $(\mathrm{n}=$ 532) and the normality of the data suggest that there is unlikely to be a problem.

To conclude, the current study has confirmed acceptable psychometric properties for the MSRS-CC, which was developed to measure Chinese pre-adolescents' propensity to consciously attend to and control their movements. The MSRS-CC potentially is a research tool that can be used to advance our understanding of conscious attention and control in motor behaviour in a variety of clinical and educational settings that underlie physical activity by children.

\section{Acknowledgement}

The authors are grateful for support from the Research Grants Council of the Hong Kong Special Administrative Region (HKU 748709H) and the Public Health and Sciences of Learning Strategic Research Themes of the University of Hong Kong. Tsang Fan Pong is thanked for his technical support.

The second author, Dr Jon Maxwell, passed away on 25 January, 2009, while this study was under preparation. It is a privilege to have worked with Jon. His enthusiasm for the research and his sharp humour is dearly missed by us all.

\section{References}

Anderson, J. C., \& Gerbing, D. W. (1988). Structural equation modeling in practice: A review and recommended two-step approach. Psychological Bulletin, 103, 411-423.

Arbuckle, J. (2003). Amos 5. Chicago: Smallwaters Corporation.

Barnett, L. M., van Beurden, E., Morgan, P. J., Brooks, L. O., \& Beard, J. R. (2009). Childhood motor skill proficiency as a predictor of adolescent physical activity. Journal of Adolescent Health, 44, 252-259.

Booth, M., Okely, A. D., Denney-Wilson, E., Hardy, L., Yang, B., \& Dobbins, T. (2006). NSW schools phsycial activity and nutrition survey (SPANS) 2004 full report (No. SHPN 060056). Sydney, New South Wales: New South Wales Department of Health.

Browne, M. W., \& Cudeck, R. (1993). Alternative ways of assessing model fit. In K. A. Bollen \& J. S. Long (Eds.), Testing structural equation models (pp. 136-162). Beverly Hills, CA: Sage.

Byrne, B. M. (1994). Testing for the factorial validity, replication, and invariance of a measuring instrument: A paradigmatic application baed on the Maslach Burnout Inventory. Multivariate Behavioral Research, 29, 289-311.

Byrne, B. M. (2010). Structural equation modeling with AMOS: Basic concepts, applications, and programming (2nd ed.). New York, NY: Routledge.

Cairney, J., Hay, J., Veldhuizen, S., \& Faught, B. E. (2011). Trajectories of cardiorespiratory fitness in children with and without developmental coordination disorder: A longitudinal analysis. British Journal of Sports Medicine, 45(15), 1196-1201. doi:10.1136/bjsm.2009.069880

Capio, C. M., Poolton, J. M., Sit, C. H. P., Eguia, K. F., \& Masters, R. S. W. (2013). Reduction of errors during practice facilitates fundamental movement skill learning in children with intellectual disabilities. Journal of Intellectual Disability Research, 57, 295-305.

Capio, C. M., Poolton, J. M., Sit, C. H., Holmstrom, M., \& Masters, R. S. (2013). Reducing errors benefits the field-based learning of a fundamental movement skill in children. Scandinavian Journal of Medicine \& Science in Sports, 23(2), 181-188. 
Chang, S. H., \& Yu, N. Y. (2010). Characterization of motor control in handwriting difficulties in children with or without developmental coordination disorder. Developmental Medicine and Child Neurology, 52 (3), 244-250.

Chell, B. J., Graydon, J. K., Crowley, P. L., \& Child, M. (2003). Manipulated stress and dispositional reinvestment in a well-volley task: An investigation into controlled processing. Perceptual Motor Skills, 97 (2), 435-448.

Cortina, J. M. (1993). What is coefficient alpha? An examination of theory and applications. Journal of Applied Psychology, 78, 98-104.

Cremeens, J., Eiser, C., \& Blades, M. (2006). Characteristics of health-related self-report measures for children aged three to eight years: A review of the literature. Quality of Life Research, 15, 739-754.

Dunn, T. J., Baguley, T., \& Brunsden, V. (2014). From alpha to omega: A practical solution to the pervasive problem of internal consistency estimation. British Journal of Psychology, 105(3), 399-412. doi:10. 1111/bjop.12046

Finney, S. J., \& DiStefano, C. (2006). Nonnormal and categorical data in structural equation models. In G. F. Hancock \& R. O. Mueller (Eds.), A second course in structural equation modeling (pp. 269-314). Greenwich, CT: Information Age.

Hands, B. (2008). Changes in motor skill and fitness measures among children with high and low motor competence: A five-year longitudinal study. Journal of Science and Medicine in Sport, 11, 155-162.

Hardy, L. L., Reinten-Reynolds, T., Espinel, P., Zask, A., \& Okely, A. D. (2012). Prevalence and correlates of low fundamental movement skill competency in children. Pediatrics, 130(2), e390-e398. doi:10.1542/ peds.2012-0345

Harrell, J. S., Pearce, P. F., Markland, E. T., Wilson, K., Bradley, C. B., \& McMurray, R. G. (2003). Assessing physical activity in adolescents: Common activities of children in 6th-8th grades. Journal of the American Academy of Nurse Practitioners, 15, 170-178.

Hau, K. T., Sung, R. Y. T., Yu, C. C. W., Marsh, H. W., \& Lau, P. W. C. (2005). Factorial structure and comparison between obese and non-obese Chinese children's physical self-concept. In H. W. Marsh, R. G. Craven, \& D. M. McInerney (Eds.), New frontiers for self-research: International advances in self research (Vol. 2, pp. 257-278). Greenwich, CT: Information Age Publishing.

Hu, L. T., \& Bentler, P. M. (1999). Cutoff criteria for fit indexes in covariance structure analysis: Conventional criteria versus new alternatives. Structural Equation Modeling, 6, 1-55.

Jackson, R. C., Ashford, K., \& Norsworthy, G. (2006). Attentional focus, dispositional reinvestment, and skilled motor performance under pressure. Journal of Sport and Exercise Psychology, 28(1), 49-68.

Kleynen, M., Braun, S. M., Beurskens, A. J., Verbunt, J. A., de Bie, R. A., \& Masters, R. S. (2013). Investigating the Dutch movement-specific reinvestment scale in people with stroke. Clinical Rehabilitation, 27(2), 160-165.

Kline, P. (1999). Handbook of psychological testing (2nd ed.). London: Routledge.

Kline, R. B. (2012). Principles and practice of structural equation modeling (2nd ed.). New York, NY: The Guilford Press.

Larson, J. C., Mostofsky, S. H., Goldberg, M. C., Cutting, L. E., Denckla, M. B., \& Mahone, E. M. (2007). Effects of gender and age on motor exam in typically developing children. Developmental Neuropsychology, 32(1), 543-562.

Ling, F. C. M., McManus, A. M., Masters, R. S. W., \& Polman, R. C. J. (2014). How useful is the Rehearsal Scale for Children - Chinese in measuring emotional rehearsal in pre-adolescents of different ages? Southeast Asia Psychology Journal, 2, 1-19.

Lingam, R., Jongmans, M. J., Ellis, M., Hunt, L. P., Golding, J., \& Emond, A. (2012). Mental health difficulties in children with developmental coordination disorder. Pediatrics, 129(4), e882-891. doi:10. 1542/peds.2011-1556

Malhotra, N., Poolton, J. M., Wilson, M. R., Ngo, K., \& Masters, R. S. W. (2012). Conscious monitoring and control (reinvestment) in surgical performance under pressure. Surgical Endoscopy, 26(9), 2423-2429.

Marsh, H. W., Marco, I. T., \& Abçý, F. H. (2002). Cross-cultural validity of the Physical Self-Description Questionnaire: Comparison of factor structures in Australia, Spain, and Turkey. Research Quarterly in Exercise and Sport, 73(3), 257-270.

Marsh, H. W., Martin, A. J., \& Jackson, S. (2010). Introducing a short version of the Physical Self Description Questionnaire: New strategies, short-form evaluative criteria, and applications of factor analyses. Journal of Sport and Exercise Psychology, 32, 438-482.

Marsh, H. W., Richards, G. E., Johnson, S., Roche, L., \& Tremayne, P. (1994). Physical Self-Description Questionnaire: Psychometric properties and a multitrait-multimethod analysis of relations to existing instruments. Journal of Sport and Exercise Psychology, 16, 270-305. 
Masters, R. S. W., Eves, F. F., \& Maxwell, J. (2005, August). Development of a movement specific reinvestment scale. Paper presented at the ISSP 11th World Congress of Sport Psychology Sydney, Australia.

Masters, R. S. W., Hall, H. S., MacMahon, K. M. A., \& Eves, F. F. (2007). Duration of Parkinson disease is associated with an increased propensity for "reinvestment". Neurorehabilitation and Neural Repair, 21 (2), 123-126.

Masters, R. S. W., \& Maxwell, J. (2008). The theory of reinvestment. International Review of Sport and Exercise Psychology, 1(2), 160-183.

Masters, R. S. W., Polman, R. C. J., \& Hammond, N. V. (1993). 'Reinvestment': A dimension of personality implicated in skill breakdown under pressure. Personality and Individual Differences, 14(5), 655-666.

Maxwell, J. P., Masters, R. S. W., \& Hammond, J. (2008, July). Interactions between implicit/ explicit learning and fundamental movement ability in children. Paper presented at the 13th European College of Sports Science Annual congress, Estoril, Portugal.

Maxwell, J. P., Masters, R. S. W., \& Poolton, J. (2006). Performance breakdown in sport: The roles of reinvestment and verbal knowledge. Research Quarterly for Exercise and Sport, 77(2), 271-276.

Nunnally, J. C., \& Bernstein, I. H. (1994). Psychometric Theory. New York, NY: McGraw-Hill.

Orrell, A. J., Masters, R. S., \& Eves, F. F. (2009). Reinvestment and movement disruption following stroke. Neurorehabilitation and Neural Repair, 23(2), 177-183. doi: 10.1177/1545968308317752

Pang, A. W., \& Fong, D. T. (2009). Fundamental motorl skill proficiency of Hong Kong children aged 6-9 years. Research in Sports Medicine, 17(3), 125-144.

Peens, A., Pienaar, A. E., \& Nienaber, A. W. (2008). The effect of different intervention programmes on the self-concept and motor proficiency of 7- to 9-year-old children with DCD. Child: Care, Health and Development, 34(3), 316-328. doi:10.1111/j.1365-2214.2007.00803

Piek, J. P., Baynam, G. B., \& Barrett, N. C. (2006). The relationship between fine and gross motor ability, self-perceptions and self-worth in children and adolescents. Human Movement Science, 25(1), 65-75.

Portney, L.G., \& Watkins, M.P. (2000). Foundations of clinical research: Applications to practice. Upper Saddle River, NJ: Prentice Hall Health.

Pratt, M. L., \& Hill, E. L. (2011). Anxiety profiles in children with and without developmental coordination disorder. Research in Nursing and Health, 32, 1253-1259.

Rivilis, I., Hay, J., Cairney, J., Klentrou, P., Liu, J., \& Faught, B. E. (2011). Physical activity and fitness in children with developmental coordination disorder: A systematic review. Research in Developmental Disabilities, 32(3), 894-910.

Stevens, J. (2002). Applied multivariate statistics for the social sciences. New York, NY: Routledge.

Streiner, D. L., \& Norman, G. R. (2008). Health measurement scales: A practical guide to their development and use (4th ed.). New York, NY: Oxford University Press.

Tabachnick, B. G., \& Fidell, L. S. (2007). Using multivariate statistics (5th ed.). New York, NY: Harper \& Row.

Thomas, J. R., \& French, K. E. (1985). Gender differences across age in motor performance: A meta-analysis. Psychological Bulletin, 98, 260-282.

Tice, D.M., Buder, J., \& Baumeister, R.F. (1985). Development of self-consciousness: At what age does audience pressure disrupt performance? Adolescence, 20(78), 301-305.

Weng, L.-J. (2004). Impact of the number of response categories and anchor labels on coefficient alpha and test-retest reliability. Educational and Psychological Measurement, 64(6), 956-962.

Wang, T. N., Tseng, M. H., Wilson, B. N., \& Hu, F. C. (2009). Functional performance of children with developmental coordination disorder at home and at school. Developmental Medicine and Child Neurology, 51(10), 817-825. doi:10.1111/j.1469-8749.2009.03271.x

Wong, W. L., Masters, R. S., Maxwell, J. P., \& Abernethy, A. B. (2008). Reinvestment and falls in community-dwelling older adults. Neurorehabilitation and Neural Repair, 22(4), 410-414. doi:10.1177/ 1545968307313510

Wrotniak, B. H., Epstein, L. H., Dorn, J. M., Jones, K. E., \& Kondilis, V. A. (2006). The relationship between motor proficiency and physical activity in children. Pediatrics, 118(6), e1758-1765.

Zhu, F., Poolton, J., Wilson, M., Maxwell, J., \& Masters, R. (2011). Neural co-activation as a yardstick of implicit motor learning and the propensity for conscious control of movement. Biological Psychology, 87(1), 66-73. 
Appendix 1. Corresponding items of the movement-specific reinvestment scale for Chinese children (MSRS-CC) in the original movement-specific reinvestment scale (MSRS; Masters, Eves, \& Maxwell, 2005)

The following questions refer to movements that you perform in your everyday life. Please circle the answer that best describes you for each question. There is no right or wrong answer to each question. 以下所有句子是有關常生活做的動作, 請細心閲讀並圈出你認為最適合的答案。而答案並没分

1. I remember the times when my movements have failed me. ${ }^{\mathrm{a}}$

就算是很輕微的動作錯誤, 你會否記著呢?

2. If I see my reflection in a shop window, I will examine my movements. ${ }^{\text {b }}$ 如果你在店舖櫥窗看到自己的倒影, 你會否仔細觀察自己的動作?

3. I reflect about my movement a lot. ${ }^{\mathrm{a}}$ 你會否反思自己曾做過的動作?

4. I try to think about my movements when I carry them out. ${ }^{\mathrm{a}}$ 做動作時, 你會否想著將要做的動作?

5. I am self-conscious about the way I look when I am moving. ${ }^{\text {b }}$ 你會否很在意自己在做動作時的樣子?

6. I sometimes have the feeling that I am watching myself move. ${ }^{\mathrm{b}}$ 你會否覺得在自己的腦子裡看到自己做的動作?

7. I am aware of the way my body works when I am carrying out a movement. ${ }^{a}$ 當做動作時, 你會否會留意到你想做的動作與做出來的動作是否一致?

8. I am concerned about my style of moving. ${ }^{\text {b }}$ 你會否留意自己做動作時的姿態?

9. I try to figure out why my actions failed. ${ }^{a}$ 你會否嘗試去找尋動作上出錯的原因?

10. I am concerned about what people think about me when I am moving. ${ }^{\text {b }}$ 做動作時, 你會否在意別人怎樣想你?

${ }^{\mathrm{a}}$ Items representing CMP.

Items representing MSC. 